\title{
New aspects of stomatal opening mechanism
}

\author{
Joon Sang Lee ${ }^{1}$ \\ ${ }^{1}$ Chungbuk National University
}

July 16, 2020

\begin{abstract}
In the mechanisms of stomatal opening, the transports of osmotic materials between the guard cell cytoplasm and vacuole have not been studied much. There were also important lacks of understanding about tonoplast transport proteins and channels. Tonoplast has been found to have many types of channels related to $\mathrm{K}+$ transport, among which are inward-K+ channels/FV, outward-K+ channels/FV, outward-TPK/VK channels and TPC1/SV channels. The two H+ transport enzymes in tonoplast, $\mathrm{H}+-\mathrm{ATPase}$ and $\mathrm{H}+$-PPase, transport $\mathrm{H}+$ from the cytoplasm to vacuole very actively. They serve to create an ideal $\mathrm{pH}$ condition between vacuole and cytoplasm to facilitate the many metabolisms in the cell. The cytosolic K+ cannot easily enter the vacuole to fill the charge balances, because vacuole is too full of positive charges. Therefore, in order to increase the osmotic pressure of the guard cell vacuole, it is necessary to transport solute that can replace $\mathrm{K}+$. Tonoplast contains sucrose- $\mathrm{H}+$ antiports, an active transport protein that can transport cytoplasmic sucrose to vacuole. Although various solutes including $\mathrm{K}+$ are required for stomata to open, sucrose is believed to be the most important substance that can increase the vacuole's osmotic pressure.
\end{abstract}

\section{Introduction}

Starch-sugar hypothesis was the basic concept of stomatal physiology in the early 20th century. This theory was brought up by Kohl in 1895 . When the plant receives light, photosynthesis occurs, the amount of $\mathrm{CO}_{2}$ in the cell decreases, the $\mathrm{pH}$ of the guard cell increases. At high $\mathrm{pH}$, starch phosphorylase, which decomposes starch into sucrose, is activated, increasing the osmotic pressure of the guard cell. On the contrary, it was considered that the photosynthesis did not occur in the dark-treated leaves, resulting in an increase of $\mathrm{CO}_{2}$ concentration. As a result, at low $\mathrm{pH}$, the starch does not decompose into sucrose and the stomata close. It is now known that in the distribution of carbon, carbon assimilated by photosynthesis during the day is used for starch synthesis of chloroplasts or transported to the cytoplasm for sucrose synthesis.

Therefore, the initial starch-sugar theory is not perfect, but it is still a partially accepted theory that it was understood as a sucrose as the main osmotic material that opens stomata.

In 1943, Imamura isolated epidermis from the mesophyll cells and cultured epidermal strips in a high concentration of $\mathrm{KCl}$ solution. And then, he observed an increase of $\mathrm{K}^{+}$concentration in the guard cell. Experimented in the same way as Imamura, in 1976, Hsiao announced that the accumulation of $\mathrm{K}^{+}$occurs when stomata open. From this point on, many stomatal researchers began to see $\mathrm{K}^{+}$as the main osmotic material for stomata opening. In 1996, when stomata were opened, a paper was published stating that up to $800 \mathrm{mM}$ of $\mathrm{K}^{+}$was accumulated in the guard cell (Talbott et al . 1996). Even today, many scientists understand that stomatal opening is caused by $\mathrm{K}^{+}$. Environmental factors, such as light and $\mathrm{CO}_{2}$ concentration, trigger events, which may result in stomatal opening. However, currently still, how these signals are sensed and how they are transduced into driving osmotic materials, which control stomatal movements, are not fully understood. Some of the stomatal researchers actually measured the $\mathrm{K}^{+}$concentration of the guard cell to see if it needed so much potassium for the stomatal opening (Travis \& Mansfield 1977, Bowling 1987, DeSilva et al . 1996). When the $\mathrm{K}^{+}$concentration of the guard cell was measured, the total concentration 
of $\mathrm{K}^{+}$ions presents in the cytoplasm, apoplast, and vacuole was $100^{\sim} 150 \mathrm{mM}$, and most $\mathrm{K}^{+}$was known to exist in the apoplast $\left(50^{\sim} 75 \mathrm{mM}\right)$.

The above results showed that the concentration of $\mathrm{K}^{+}$for stomatal opening was not higher than expected. In this confused state, the osmotic material needed for stomatal opening was considered to be sucrose, as in early theory (Outlaw 1989, Reckmann et al . 1990, Gautier et al . 1991, Poffenroth et al . 1992, Outlaw 1996, Lu et al . 1997, Asai et al . 2000, Outlaw \& De Vleighere 2001, Lawson et al . 2002, 2003, von Caemmerer et al . 2004, Outlaw 2003, Kang et al . 2007).

Currently, according to stomatal researchers, $\mathrm{K}^{+}$or sucrose is believed to be the main osmotic material, so two types of theories are compatible. Of course, for stomatal opening, most stomatal researchers recognize that $\mathrm{Cl}^{-}$and malte- are necessary in addition to $\mathrm{K}^{+}$and sucrose. It has been found that $\mathrm{K}^{+}$and sucrose can act similarly for stomatal opening (Tallman \& Zeiger 1988). They reported that stomata were opened by k $\mathrm{k}^{+}$ in the early morning and sucrose acts as an osmotic material in the afternoon. Zeaxanthin and phototropins (pho1 andpho2 ), blue light photoreceptors for stomatal openings, have been identified. Blue light has been shown to promote regulatory 14-3-3 protein, as the activity of PM (plasma membrane) $\mathrm{H}^{+}$-ATPase by IAA is mediated by regulatory 14-3-3 protein (Eigo \& Kinoshita 2018). However, despite the discovery of a mechanism for stomatal opening by blue light, stomata are also opened by red and white light. The size of the stomatal apertures caused by white light was about $18 \mu \mathrm{m}$ in Commelina communis, but increased by about $6 \mu \mathrm{m}$ stomatal aperture by single blue light and stomatal aperture of about $7.3 \mu \mathrm{m}$ by red light (Schwarz \& Zeiger 1984, Lee \& Bowling 1992). The stomatal aperture by blue light was estimated to be the sum of the stomatal opening by chlorophyll and carotenoid and the stomatal opening mediated by blue light photoreceptors. Indeed, experiments with stomatal aperture measurements associated with blue light receptors have been described by Talbott et al . (2003) is the only one. After the blue light receptors-deficient mutant plants were made inArabidopsis thaliana, the stomatal opening by blue light was observed. In wild type, stomatal opening increased by about $0.7 \mu \mathrm{m}$ when treated with blue light, but stomatal opening of the npq1 mutant was suppressed by about $0.3 \mu \mathrm{m}$. The photo1 / photo2 mutant had a rather increased stomatal opening of about $0.3 \mu \mathrm{m}$. In the experiment using the blue photoreceptor mutation, the wild type increased about $0.4 \mu \mathrm{m}$ compared to the photo1/photo2 mutant. SEM (The standard errors of the mean) of about 20 stomatal apertures repeated twice in the Commelina communis was $\pm 0.89 \mu \mathrm{m}$ (Lee \& Bowling 1992). Therefore, it is difficult to see that the effect of the distinct blue light receptor appeared in Talbott et al '. (2003)'s experiment.

Recently, stomatal researchers who studied stomata in relation to blue light photo-receptors were difficult to find, but review papers were available (Inoue \& kinoshita 2017, Matthews et al . 2020). Therefore, in this paper, the environmental characteristics of ion and sucrose transport between the guard cell cytoplasm and vacuole are examined, and attempts are made to clarify the opinions on stomatal opening by blue light.

\section{Plant growth and photosynthesis could occur under single blue light}

In the 1960s, mechanisms for photosynthetic electron transport have been revealed, which is the fact that electron transport is centered around photosystem II (P680) and photosystem I (P700). Since then, it was recognized that photosynthesis was caused mainly by red light. In 1882, Engelmann used a prism to disperse sunlight into a rainbow, then illuminated aquatic filaments, Spirogyra sp. and observed the migration of the $\mathrm{O}_{2}$-seeking bacteria population. As a result, $\mathrm{O}_{2}$-seeking bacteria gathered at the sites that generate the most oxygen, where the similar numbers of bacteria gathered at blue and red light regions. This experiment was surprisingly the first to show that photosystem II works perfectly by single blue light only. Recently, many papers were reported that photosynthetic electron transport by blue light occurred perfectly (Evans et al . 2017, Gruszecki et al . 1997, Miao et al . 2015). The absorption spectrum regions of chlorophyll a and $\mathrm{b}$ are much larger and have a wider range than red light region. The absorption spectrum of chlorophyll $\mathrm{b}$ showed the peak between $400^{\sim} 500 \mathrm{~nm}$ and the absorption spectrum of the red light showed peak between $600^{\sim} 700 \mathrm{~nm}$. The sizes of blue light absorption spectrum region are twice higher than that of red light in chlorophyll b. The highest absorption spectrum of chlorophyll a showed a larger and broader absorption spectrum from 300 to $450 \mathrm{~nm}$ than the highest red light absorption spectrum in 670nm (Comar \& Zscheile 
1942). $\beta$-carotene absorbs only the regions of blue light band. These facts imply that the main absorption spectrum of chlorophyll is blue wavelength, which is very important for photosynthetic activities. It was reported that blue light increased net leaf photosynthetic rates when those are compared to red light alone in wheat (Goins et al . 1997). Only $50 \%$ blue light doubled the photosynthetic activities over red light alone (Hogewoning et al . 2010). The most surprising facts are that plants could grow only with red or blue light. The seedlings of Salvia splendens F. Sello ex Roem \& Schult. were treated with only blue light for 4 weeks and then growths were observed for the first time (Runcle 2017). In the absence of blue radiation, the plants had purplish leaves. However, in outdoors, the plants had green leaves. Seedlings grown indoors with blue light were often shorter and had smaller leaves than grown under only red light. They also observed the induction of flowers from Salvia splendens which was grown under the only blue light. Two rose cultivars, Rosa hybrid 'Radrazz' andRosa chinensis 'Old blush', were cultivated under blue or white light. While plant development was totally inhibited in darkness, blue light could sustain full development from bud burst until flowering (Abidi et al . 2013). These mean that the plants operate photosynthetic electron transports and the Calvin cycles even though they were only treated by blue light. It was reported that blue light was more essential than red light for the activities of photosystem II and I in cucumber leaves (Miao et al . 2016). The similar effects of blue light on biochemical composition and photosynthetic rate ofIsochrysis sp. were reported by Marcetti et al . (2013). Mesembryanthemum crystallinum was cultured aeroponically for a 16-h photoperiod at an equal photosynthetic photon flux density of $350 \mu \mathrm{mol} \mathrm{m} \mathrm{m}^{-2} \mathrm{~s}^{-1}$ under red and blue light. Compared to plants grown under red light condition, blue light treated plants had similar but higher total chlorophyll contents, carotenoid contents and higher Chl. $a$ / $b$ ratios (He et al . 2017). Blue light perfectly performs $\mathrm{CO}_{2}$ assimilation as well as photosynthetic electron transport (Abidi et al . 2013).

The study of stomatal opening by blue light began with the idea that photosynthetic activities were induced only by red light. In the studies of the stomatal opening mechanism, those were recognized that the treatment of red light as a background could eliminate all photosynthetic effects and observed the stomatal opening reactions by blue light. Surprisingly, the studies of the stomatal opening mechanisms caused by the blue light originated from this experimental prerequisite. Nevertheless, some stomatal researchers did not think that blue light was essential for the activities of photosynthesis.

Fig. 1. The possible mechanisms of stomatal opening. The explanations of the figure are below.

\section{Is IAA the first essential signal hormone for the stomatal opening?}

The hypothesis which is still widely accepted to explain stomatal activities involves fluxes of inorganic cations and anions across the plasma membrane and tonoplast of guard cells associated with the synthesis and degradations of photosynthetic products. It was reported that previously darkened leaves expose to light showed quenching of fluorescence in the apoplast surrounding the guard cells up to 20 min. before stomatal opening (Edwards et al . 1988). They showed that proton efflux originating at the guard cells preceded stomatal opening, confirming earlier works which suggested that proton efflux was a necessary precursor of stomatal opening (Raschke \& Humble 1973). Therefore, when stomata open, protons are first pumped out from the guard cell, resulting in hyperpolarization of plasma membrane potential difference. Consequently, $\mathrm{K}^{+}$may then passively enter guard cell cytoplasm from the guard cell wall or subsidiary cells. Therefore, the first reaction that occurs when stomata are opened, is the activity of PM (plasma membrane) $\mathrm{H}^{+}$-ATPase present in the guard cell. How does $\mathrm{PM} \mathrm{H}^{+}$-ATPase activate? It can be assumed that $\mathrm{PM} \mathrm{H} \mathrm{H}^{+}$-ATPase can be activated by light simply because stomata open when plants receive light and stomata close in the dark. Very important points here are understandings of the structures and activities of PM H $\mathrm{H}^{+}$-ATPase. PM H $\mathrm{H}^{+}$-ATPase can be activated by phosphorylation of their penultimate residue (a Thr) and the subsequent binding of regulatory 14-3-3 proteins. The confusions are that PM $\mathrm{H}^{+}$-ATPase is activated by regulatory 14-3-3 proteins by IAA, fusicoccin and light (Olsson et al . 1998, Svennelid et al . 1999, Takahashiet al . 2012, Eigo \& Kinoshita 2018). These results suggest that the first signal material required for stomata to open can be IAA or light. Therefore, it means that the initial signal transduction pathway of stomatal opening can be induced by light regardless of IAA. However, delicate reactions such as stomatal opening require light, but it must be speculated that the IAA, which acts as a signal for cell 
wall growth, phototropism, thigmotropism, and many metabolisms of plants as a signal material, is highly likely to be the first signal material for stomatal opening (Fig. 1). Plant V (vacuolar)- $\mathrm{H}^{+}$-ATPase and $\mathrm{H}^{+}$-ppase maintain the vacuole acidity, so their activities are obvious. IAA transports to guard cells through PGP/ABCB using ATP in the plasma membrane of the mesophyll cells (Fig. 1). The main synthesis sites for IAA are the cytoplasms of young leaf mesophyll cells, which are also synthesized in mature leaves (Fig. 1). IAA promotes the activity of $\mathrm{PM} \mathrm{H}^{+}$-ATPase to acidify the cell wall. Plant $\mathrm{V}-\mathrm{H}^{+}$-ATPase could be also activated by IAA. This is because PM $\mathrm{H}^{+}$-ATPase and $\mathrm{V}^{-} \mathrm{H}^{+}$-ATPase are monophyly, so they have high phylogenetic relationships, similar structures and functions. The high activities of many $\mathrm{V}-\mathrm{H}^{+}-\mathrm{ATPase}$ and $\mathrm{H}^{+}$-ppase promote $\mathrm{H}^{+}$transport to vacuole and increases sucrose transport to vacuole by $\mathrm{H}^{+}$-sucrose antiporters to balance $\mathrm{H}^{+}$charges (Fig. 1). It was also reported that the transcription of $\mathrm{H}^{+}$-PPase gene IbVP1 in sweet potato plants was strongly induced by auxin in hydroponics (Fan et al . 2017).

Sucrose is the main osmotic material for the stomatal opening and most of sucrose comes from the mesophyll cells

Sucrose is much more efficient osmotic material than $\mathrm{K}^{+}$ions. The sucrose in increasing the spacing of the water solution was mainly responsible for osmotic potential; this contrasted with $\mathrm{K}^{+}$and $\mathrm{Cl}^{-}$ions where their spacing effects were only a little higher to that of water held to those ions (Cochrane \& Cochrane 2007).

During the day, Sucrose synthesized in the cytoplasm of mesophyll cells is actively transported to the guard cell by the $\mathrm{H}^{+}$-sucrose symport through the plasma membrane (Fig. 1). All plant cells usually have plasmodesmata. However, guard cells initially are coupled symplastically to adjoining epidermal cells. With time, however, their plasmodesmata become truncated and eventually nonfunctional, eliminating intercellular communication between mature guard cells and surrounding epidermal cells (Roberts \& Oparka 2003). When the $\mathrm{pH}$ of the vacuole is acidic, $\mathrm{Cl}^{-}$and malate ${ }^{2-}$ may be transported to the vacuole for the charge balances (Fig. 1). Humble and Raschke (1971) reported that only $5 \%$ of $\mathrm{K}^{+}$was balanced by $\mathrm{Cl}^{-}$inCommelina communis. In the same species, the accumulation of malate ${ }^{2-}$ could account for half of the $\mathrm{K}^{+}$uptake (Allaway 1973). At that time, the stomatal researchers believed that the stomatal opening was caused by $\mathrm{K}^{+}$. However, if the main osmotic material was supposed to be sucrose, the importance of $\mathrm{Cl}^{-}$and malte ${ }^{2-}$ as the osmotic materials needed for stomata to open will be lower.

Assuming that sucrose is the main osmotic material of the stomatal opening, sucrose has to be transported from mesophyll cells. It is generally accepted that all Calvin-Benson cycle enzymes are present and functional in guard cells, but their activities of the chloroplasts definitely low, and they cannot supply all the osmotic materials to guard cells (Lawson et al . 2002, 2003). If the guard cell itself could not supply all the requirements of the energy, then imports from the mesophyll cells must occur (Outlaw 1989, Reckman et al . 1990). It has been observed that pulse-labelling solutes are actively transferred from labelled mesophyll cells to the epidermis (Outlaw \& Fisher 1975, Outlaw et al . 1975). There were rapid exchanges of photosynthetic products between the mesophyll and epidermis. These metabolites include glucose, sucrose, sugar phosphates, malate, glycine and serine (Thorpe \& Milthorph 1984). Guard cells usually contain from 10 to 15 chloroplasts. In case of Selaginella, the number of guard cell chloroplast were 36 . Erigeron annuus (L.) PERS. had 9 chloroplasts per guard cell: Sedum sarmentosum, 7; Chamaesyce supina MOLD, 8; Trifolium repens , 7;Persicaria tinctoria , 9; Portulaca oleracea L., 8) (Lee \& Park 2016). In the early days, plant without chloroplasts in the guard cells was firstly known in Paphiopedilum insigna var. (Nelson \& Mayo 1975). The succulent plant, Pelagonium zonale cv.Chelsia gem . have no chloroplasts in guard cells (Avrill \& Willmer 1984). Slow photosynthetic induction and low photosynthesis inPaphiopedilum armeniacum are related to its lack of guard cell chloroplast and peculiar stomatal anatomy (Zhang et al . 2011). Although these plants do not have chloroplasts in the guard cell, stomata work normally, meaning that these guard cells are sink cells that must receive photosynthetic products from mesophyll cells.

The thickness of the guard cell wall can be reach about $5 \mu \mathrm{m}$ and the width of mesophyll cell wall is only under $100 \mathrm{~nm}$ (depicted in Fig. 1). It is estimated that about $90 \%$ sucrose of the total amount needed by the guard cell comes from mesophyll cells. $80 \%$ of which may be transported to vacuole, and $10 \%$ of which can be used for maintenances and repairs of guard cells including the wall structures (Fig. 1). Sucrose 
synthesized by guard cell chloroplasts may be under $10 \%$. It could be estimated that about $5 \%$ sucrose may be transported to vacuole, and the rest can be used for maintaining the structure of the guard cell wall and metabolism in the guard cell (Fig. 1).

\section{What is the role of $\mathrm{K}^{+}$for the stomatal opening?}

Stomata open slowly without lag time under the sun light (Lee \& Bowling 1992). Lu et al . (1997) have pulse-labelled the leaflets of broad bean with ${ }^{14} \mathrm{CO}_{2}$, then harvested whole leaf pieces and rinsed epidermal peels for subsequent processing in a histochemical analysis. There, sucrose-specific radioactivity shows a peak $\left(111 \mathrm{GBq} \mathrm{mol}{ }^{-1}\right)$ in the palisade cells at $20 \mathrm{~min}$. Therefore, when the plant receives light, sucrose uptake into the guard cell vacuole could occur firstly. According to the increases of photosynthetic activities in mesophyll cells over time, stomatal apertures increase as the synthesized sucrose accumulations into vacuole. The number of chloroplasts in mesophyll cells is known to be unexpectedly high. It is expected that the number of chloroplasts in mesophyll cells may vary depending on the plant species. For the first time, the number of chloroplasts in mesophyll cells was measured using an optical microscope and reported to reach up to 70 (Humble \& Rashke 1971). Zuzana et al. (2014) applied, for the first time, the stereological method of an optical dissector based on counting chloroplasts in stacks of spruce needle optical cross-sections acquired by confocal laser-scanning microscopy. They reported that, unlike what was measured with a two-dimensional optical microscope, when measured with a three-dimensional microscope, the number of chloroplasts increased by about ten times. Therefore, they estimated that chloroplasts in mesophyll cells reached hundreds. According to a recent report, the number of chloroplasts in mesophyll cells was generally estimated to 100 (Lee 2019). However, the number of chloroplasts in Fig. 1 was comprehensively reviewed and displayed as $60^{\sim} 100$. Except for apoplast, the remaining $\mathrm{K}^{+}$concentration of $5075 \mathrm{mM}$ will be divided into cytoplasm or vacuole. According to the activity of $\mathrm{PM} \mathrm{H}^{+}$-ATPase, $\mathrm{K}^{+}$concentration of the cytoplasm will increase as $\mathrm{K}^{+}$is transported to the cytoplasm. Some of the increased $\mathrm{K}^{+}$in the cytoplasm will be transported to the vacuole (Fig. 1). Tonoplast has with very selective $\mathrm{K}^{+} / \mathrm{FV}$-inward and outward channels (Lebaudy et al . 2007). Since these two-channels are shaker channels that are activated equally by voltage, it is presumed that the difference in slope between $\mathrm{K}^{+}$concentrations of vacuole and cytoplasm will not be large. TPK/VK channels present in the tonoplast, which are very selective to $\mathrm{K}^{+}$ions and release $\mathrm{K}^{+}$ into the cytoplasm. Tonoplast also have TPC1/SV channels that transports two ions of $\mathrm{K}^{+}$and $\mathrm{Ca}^{2+}$ to the cytoplasm non-selectively (Fig. 1). Therefore, it is presumed that the transport of $\mathrm{K}^{+}$to vacuole from cytoplasm will be limited (Fig. 1). V-H $\mathrm{H}^{+}$-ATPase and $\mathrm{H}^{+}$-ppase are present in tonoplast, and they transport cytoplasmic $\mathrm{H}^{+}$into vacuole. Therefore, vacuolar $\mathrm{pH}$ maintains generally around $5 \sim 5.5$ (Fig. 1). It was also reported that vacuolar $\mathrm{pH}$ was below 3 in 9 plant species. The fruit vacuolar $\mathrm{pHs}$ in Citrus aurantifolia and Prunus cerasus were 1.7 and 2.5 , respectively. The leaf vacuolar $\mathrm{pH}$ of the very common Rumex sp. was 2.6, and the vacuolar $\mathrm{pH}$ of the lowest plant, Perpetual begonia, was 0.9 1.4 (Small 1946). This means that tonoplast has a strong ability to transport cytosolic $\mathrm{H}^{+}$to vacuole. In this state, $\mathrm{K}^{+}$transport by tonoplast-inward $\mathrm{K}^{+}$channels must be limited (Fig. 1).

\section{Conclusion}

Algae does not have guard cells. Intercellular space is well developed for gas exchange and supporting action in leaves of aquatic plants, and intercellular space is connected to guard cells. Leaves submerged in water have no stomata, whereas leaves floating on water have guard cells in the upper epidermis. Evolutionally, guard cells are a new apomorphy from algae. The evolution of the stomata was derived from the process in which algae evolved into terrestrial plants. Guard cells are present in the leaves of bryophytes, fern and almost all vascular plants. The basic role of stomata is to minimize water stress and to maximize the efficiency of photosynthesis activity through photosynthesis and transpiration. Photosynthesis plays a central role in the physiology of plants and the understandings of its response to light are, therefore, critical to any discussion of how plants sense and respond to light. It is likely that many responses exhibited by plants to light are in fact mediated by the response of photosynthesis (Lee 2019). The stomatal mechanism could be controlled by the command and the operation. This suggests the idea that the stomata should be controlled according to the demand of the mesophyll cells. In this hypothesis, the command originates in the 
mesophyll cells and the operation in guard cells (Lee \& Bowling 1995). About $95 \%$ of total photosynthesis in plants occurs in mesophyll cells of the leaves (Lee 2016). Therefore, it is assumed that the photosynthesis products, inorganic ions and hormones, are very likely to be transported between the guard cells and the mesophyll cells. Chloroplasts in mesophyll cells have evolved optimally for photosynthesis for hundreds of millions of years.

However, chloroplasts in guard cells have evolved to be less optimized for photosynthesis. This may be seen as a reduction in the role of chloroplasts in the guard cell or a decrease in photosynthetic activity. There were much lacks of understanding of guard cell vacuole when explaining the stomatal opening mechanism. The guard cell vacuole is normally maintained at $\mathrm{pH} 5 \sim 5.5$. It is regulated by the high activities of $\mathrm{V}$ $\mathrm{H}^{+}$-ATPase and $\mathrm{H}^{+}$-PPase in apoplast. Therefore, due to the activity of $\mathrm{V}-\mathrm{H}^{+}$-ATPase and $\mathrm{H}^{+}$-PPase in the guard cell vacuole, vacuole has a high positive charges by $\mathrm{H}^{+}$, so the transport of $\mathrm{K}^{+}$into vacuole through the inward vacuolar $\mathrm{K}^{+}$channels can be limited. Tonoplast has outward- $\mathrm{K}^{+}$-channels/FV, outwardTPK/VK-channels and TPC1/SV channels that release vacuole $\mathrm{K}^{+}$into the cytoplasm. These channels are responsible for balancing the positive charges as well as the $\mathrm{K}^{+}$concentration in the vacuole. Therefore, sucrose- $\mathrm{H}^{+}$antiporters transport sucrose to vacuole relatively easily.

\section{Conflict of Interest}

The author declare that they have no conflict of interest.

\section{References}

Abidi F., Girault T., Douillet O., Guillemain G., Sintes G., Laffaire M., Ben Ahmed H., Smiti S. \& Leduc N (2013) Blue light effects on rose photosynthesis and photomorphogenesis. Plant Biol 15, 67-74.

Allaway W.G. (1973) Accumulation of malate in guard cells of Vicia fabaduring stomatal opening.Planta110 , 63-70.

Asai N., Nakazima N., Tamaoki M., Kamada H. \& Kondo N. (2000) Role of malate synthesis mediated by phosphoenolpyruvate carboxylase in guard cells in the regulation of stomatal movements. Plant Cell Physiol41, 10-15.

Bowling D.J.F. (1987) Measurement of the apoplastic activity of $\mathrm{K}^{+}$and $\mathrm{Cl}^{-}$in the leaf epidermis of Commelina communis in relation to stomatal activity. J Exper Bot 38, 1351-1355.

Cochrane T.T. \& Cochrane T.A. (2009) Differences in the way potassium chloride and sucrose solutions effect osmotic potential of significance to stomata aperture modulation. Plant Physiol Biochem 47 , 205-209.

Comar C.L. \& Zscheile F.P. (1942) Analysis of plant extracts for chlorophyll a and b by a photoelectric spectrophotometer method.Plant Physiol $17,198-209$.

DeSilva D.L.R., Honour S.J. \& Mansfield T.A. (1996) Estimations of apoplastic concentrations of $\mathrm{K}^{+}$and $\mathrm{Ca}^{2+}$ in the vicinity of stomatal guard cells. New Phyto 134, 463-469.

Edwards M.C., Smith G.N. \& Bowling D.J.F. (1988) Guard cells extrude protons prior to stomatal opening. $J$ Exp Bot39,1541-1547.

Eigo A. \& Toshinori K. (2018) Red light-Induced phosphorylation of plasma membrane $\mathrm{H}^{+}$-ATPase in stomatal guard cells.Plant Physiol 178, 838-849.

Evans J.R., Morgan P.B. \& von Caemmerer S. (2017) Light quality affects chloroplast electron transport rates estimated from Chl fluorescence measurements. Plant Cell Physiol 58 , 1652-1660.

Fan W., Wang H., Wu Y., Yang N., Yang J. \& Zhang P. (2017) $\mathrm{H}^{+}$-pyrophosphatase IbVP 1 promotes efficient iron use in sweet potato [Ipomoea batatas (L.) Lam.]. Plant Biotech J 15, 698-712.

Gautier H., Vavasseur A., Gans P. \& Lasc G. (1991) Relationship between respiration and photosynthesis in guard cell and mesophyll cell protoplasts of Commelina communis L. Plant Physiol95 , 636-641. 
Goins G.D., Yorio N.C., Sanwo M.M. \& Brown C.S. (1997) Photomorphogenesis, photosynthesis, and seed yield of wheat plants grown under red light-emitting diodes (LEDs) with and without supplemental blue lighting. J Exp Bot 48 ,1407-1413.

Gruszecki W.L., Wardak A. \& Maksymiec W. (1997) The effect of blue light of electron transport in photosystem II reconstituted in planar bilayer lipid membrane.J Photochem Photobio B: Biol 39, 265-268.

He J., Qin L., Emma L.C., Chong E.L.C., Choong T.W. \& Lee S.K. (2017) Plant growth and photosynthetic characteristics ofSembryanthemum crystallinum grown aeroponically under different blue- and red-LEDs. Front Plant Sci 8 , 361-374.

Hogewoning S.W., Trouwborst G., Maljaars H., Poorter H., van Ieperen W. \& Harbinson J. (2010) Blue light dose-responses of leaf photosynthesis, morphology, and chemical composition of Cucumis sativus grown under different combinations of red and blue light. J Exp Bot 61, 3107-3117.

Hsiao T.C. (1976) Stomatal ion transport. In Transport in Plants (eds U. Luttge \& M.G. Pitman), pp 195-221. Springer, Berlin.

Humble G.D. \& Raschke K. (1971) Stomatal opening quantitatively related to potassium transport evidence from electron probe analysis. Plant Physiol 48 , 447-453.

Imamura S. (1943) Untersuchungen über den Mechanismus der Turgorschwankung der SpaltoffnungsSchliesszellen. Japanese J Bot12, 251-346.

Inoue S.I. \& Kinoshita T. (2017) Blue light regulation of stomatal opening and the plasma membrane $\mathrm{H}^{+}$ ATPase. Plant Physiol 174, 531-538.

Kang Y., Outlaw W.H., Anderson P.C. \& Fiore G.B. (2007) Guard cell apoplastic sucrose concentration - a link between leaf photosynthesis and stomatal aperture size in apoplastic phloem loader Vicia fabaL. Plant Cell Environ $30,551-558$.

Lawson T., Oxborough K., Morison J.I.L. \& Baker N.R. (2002) Responses of photosynthetic electron transport in stomatal guard cells and mesophyll cells in intact leaves to light, $\mathrm{CO}_{2}$ and humidity. Plant Physiol $128,52-62$.

Lawson T., Oxborough K., Morison J.I.L. \& Baker N.R. (2003) The responses of guard and mesophyll cell photosynthesis to $\mathrm{CO}_{2}, \mathrm{O}_{2}$, light, and water stress in a range of species are similar. J Exp Bot 54,1743-1752.

Lebaudy A., nor Ve'ry A.A. \& Sentenac H. (2007) $\mathrm{K}^{+}$channel activity in plants: Genes, regulations and functions. FEBS Letters 581, 2357-2366.

Lee G.B. (2016) Plant Morphology. Korea: Life Science Publishing Com.

Lee J.S. \& Bowling D.J.F. (1992) Effect of the mesophyll on stomatal opening in Commelina communis . $J$ Exp Bot 43 , 951-957.

Lee J.S. \& Bowling D.J.F. (1995) Influence of the mesophyll on stomatal opening. Australian J Plant Physiol $22,357-363$.

Lee J.S. \& Park C.H. (2016) Morphological characteristics and conceptualization of guard cells in different plants. Korean J Environ Sci 25 , 1289-1297.

Lee J.S. (2019) The sustainable reasons of controversy over the mechanisms for the stomatal opening. $J$ Plant Biol 62 , 254-262.

Lu P., Outlaw W.H. Jr., Smith B.G. \& Freed G.A. (1997) A new mechanism for the regulation of stomatal aperture size in intact leaves: Accumulation of mesophyll-derived sucrose in the guard cell wall of Vicia faba . Plant Physiol 114, 109-118. 
Marchetti J., Bougaran G.T., Jauffrais T., Lefebvre S., Rouxel C., Jean B.S., Lukomska E., Robert R. \& Cadoret J.P. (2013) Effects of blue light on the biochemical composition and photosynthetic activity ofIsochrysis sp. J App Phyco 25, 109-119.

Matthews J.S.A., Vialet-Chabrand S. \& Lawson T. (2020) Role of blue and red light in stomatal dynamic behaviour $J$ Exp Bot 71, 2253-2269.

Miao Y.X., Wang X.Z., Gao L.H., Chen Q.Y. \& Qu M. (2016) Blue light is more essential than red light for maintaining the activities of photosystem II and I and photosynthetic electron transport capacity in cucumber leaves. J Inte Agri 15, 87-100.

Nelson S.D. \& Mayo J.M. (1975) The occurrence of functional nonchlorophyllous guard cells in paphiopedilum spp.Canadian J Bot $\mathbf{5 3}, 1-7$.

Olson A., Svennelid F., Ek B., Sommarin M., Larsson C. (1998) A phosphothreonine residue at the Cterminal end of the plasma membrane $\mathrm{H}^{+}$-ATPase is protected by fusicoccin-Induced $14-3-3$ binding. Plant Physiol 118, 551-555.

Outlaw W.H. \& Fisher D.B. (1975) Compartmentation in Vicia fabaleaves: Kinetics of ${ }^{14} \mathrm{C}$ in the tissues following pulse labeling. Plant Physiol 55, 699-703.

Outlaw W.H., Fisher D.B. \& Christy A.L. (1975) Compartmentation in Vicia faba leaves: 11. Kinetics of ${ }^{14} \mathrm{C}$-sucrose redistribution among individual tissues following pulse labeling. Plant Physiol 55 ,704-711.

Outlaw W.H. (1989) Critical examination of the quantitative evidence for and against $\mathrm{CO}_{2}$ fixation by guard cells. Physiol Plant 77 , 275-281.

Outlaw W H. (1996) Stomata. In: Baker NR (ed) Photosynthesis and the Environment. Dordrecht, Kluwer Academic, Dordrecht, pp 241-259.

Outlaw W.H. H. \& De Vleighere-He X. (2001) Transpiration rate: an importance factor in controlling sucrose content of the guard cell apoplast of broad bean. Plant Physiol 126 ,1717-1724.

Outlaw W.H. (2003) Integration of cellular and physiological functions of guard cells. Crit Rev Plant Sci 22 , 503-529.

Poffenroth M., Green D.B. \& Tallman G. (1992) Sugar concentrations in guard cells of Vicia faba illuminated with red or blue light.Plant Physiol $98,1460-1471$.

Raschke K. \& Humble G.D. (1973) No uptake of ions required by opening stomata of Vicia faba . Planta $115,47-57$.

Reckmann U., Scheibe R. \& Raschke K. (1990) Rubisco activity in guard cell compared with the solute requirement for stomatal opening. Plant Physiol 92, 246-253.

Roberts A.G. \& Oparka K.J. (2003) Plasmodesmata and the control of symplastic transport. Plant Cell Environ 26 , 103-124.

Runcle E. (2017) Effects of the blue light on plants. Greenhouse Product News. www.canr.msu.edu/floriculture/uploads/.../blue-light.pd...

Schwartz A. \& Zeiger E. (1984) Metabolic energy for stomatal opening: Roles of photophosphorylation and oxidative phosphorylation. Planta 161, 129-136.

Small J. (1946) pH and Plants. USA: D. van Nostrand Com. 
Svennelid F., Olsson A., Piotrowski M., Rosenquist M., Ottman C., Larsson C., Oecking C. \& Somarin M. (1999) Phosphorylation of thr-948 at the $\mathrm{C}$ terminus of the plasma membrane $\mathrm{H}^{+}$-ATPase creates a binding site for the regulatory 14-3-3 Protein. Plant Cell 11, 2379-2391.

Takahashi K., Hayashi K.I. \& Toshinori K. (2012) Auxin activates the plasma membrane $\mathrm{H}^{+}$-ATPase by phosphorylation during hypocotyl elongation in Arabidopsis . Plant Physiol159 , 632-641.

Talbott L.D. \& Zeiger E. (1996) Central roles for potassium and sucrose in guard-cell osmoregulation. Plant Physiol 111, 1051-1057.

Talbott L.D., Shimayevich I.J., Chung Y., Hammad J.W. \& Zeiger E. (2003) Blue light and phytochromemediated stomatal opening in the npq1 and phot1 phot2 mutants of Arabidopsis. Plant Physiol133 , 15221529 .

Tallman G. \& Zeiger E. (1988) Light quality and osmoregulation in Vicia guard cells: Evidence for involvement of three metabolic pathways.Plant Physiol 88, 887-895.

Thorphe N. \& Milthorphe F.L. (1984) Transport of metabolites between the mesophyll and epidermis of Commelina cyanea RBr.Australian J Plant Physiol 11 :59-68.

Travis A.J. \& Mansfield T.A. (1977) Studies of malate formation in isolated guard cells. New Phyto 78 , $541-546$.

von Caemmerer S., Lawson T., Oxborough K., Baker N.R., Andrews T.J. \& Raines C.A. (2004) Stomatal conductance does not correlate with photosynthetic capacity in transgenic tobacco with reduced amounts of Rubisco. J Exp Bot 55 , 1157-1166.

Zhang S.B., Guan Z.J., Chang W., Hu H., Yin Q. \& Cao K.F. (2011) Slow photosynthetic induction and low photosynthesis in Paphiopedilum armeniacum are related to its lack of guard cell chloroplast and peculiar stomatal anatomy. Physiol Plant 142, 118-127. 